\title{
EL EJERCICIO DE DERECHOS FUNDAMENTALES EN LA CÁRCEL: EL CASO DEL DERECHO A LA EDUCACIÓN EN LAS CÁRCELES CATALANAS
}

The exercise of fundamental rights in prison: the case of the right to education in catalan prisons

\author{
Lorena Alemán Aróstegui \\ Investigadora predoctoral contratada (FPU 18/04843) en Derecho penal \\ Universidad Pública de Navarra \\ Arnau Esteban Miralles \\ Maestro del Departament d'Educació de la Generalitat de Catalunya \\ en un Centro de Formación de Adultos/as ubicado en un Centro Penitenciario \\ Graduado en Derecho (UOC)
}

http://dx.doi.org/10.18543/ed-69(2)-2021pp15-41

Recibido: 14.10 .2021

Aceptado: 13.12.2021

\section{Resumen}

La Constitución española establece que las personas que se encuentran en la cárcel, si bien están legalmente privadas de su libertad ambulatoria, mantienen la posibilidad de ejercer el resto de sus derechos fundamentales. Sin embargo, las aproximaciones, tanto jurídicas como sociológicas, a esta cuestión visibilizan graves afectaciones al ejercicio de estos derechos. Uno de ellos es el derecho a la educación, un derecho humano y fundamental que se reconoce para todas las personas durante toda la vida, y que tiene como objetivo el pleno desarrollo de la personalidad. A pesar de la importancia de este derecho y de la centralidad de la actividad educativa en la sociedad, las problemáticas en torno a su ejercicio en el ámbito penitenciario han sido escasamente tratadas. Por eso, en este trabajo analizamos el ejercicio del derecho a la educación de las personas privadas de libertad, concretamente, en las cárceles catalanas y con una aproximación a la práctica diaria desde la 
perspectiva docente. Estudiamos el encaje de las escuelas dentro de las prisiones para tratar de determinar si existen o no limitaciones o condicionantes al ejercicio de este derecho, y cuáles son las ventajas de su presencia.

\title{
Palabras clave
}

Educación, derecho, cárcel, escuela, tratamiento.

\begin{abstract}
The Spanish Constitution establishes that inmates, although being legally deprived of their freedom of movement, maintain the possibility of exercising the rest of their fundamental rights. Yet, both legal and sociological approaches to this matter make visible serious effects on the exercise of said rights. One of them is the right to education, a fundamental and human right recognized for all people throughout life whose objective is the full development of one's personality. Despite the importance of this right and the centrality of educational activity in society, problems surrounding its exercise in a prison environment have been sparsely addressed. For this reason, in the present work we analyze the exercise of the right to education of people deprived of liberty, more specifically, in Catalan prisons, following an approach to daily practice from a teaching perspective. We study how schools fit within a prison context in an attempt to determine whether or not there are limitations or conditions to the exercise of this right, and which advantages of their presence are.
\end{abstract}

\section{Keywords}

Education, right, prison, school, treatment. 


\begin{abstract}
SUMARIO: I. El EJERCICIO DE DERECHOS FUNDAMENTALES EN LA CÁRCEL. II. LA EDUCACIÓN COMO DERECHO HUMANO Y FUNDAMENTAL. 1. El objetivo del pleno desarrollo de la personalidad. III. EL EJERCICIO DEL DERECHO A LA EDUCACIÓN EN LAS CÁRCELES CATALANAS. 1. La educación de personas privadas de libertad. Marco normativo de la educación en prisión. 2. La actividad educativa en las cárceles catalanas. 2.1. Sistema de Evaluación y Motivación (SAM). 2.2. Programa Individualizado de Tratamiento (PIT). 2.3. Perspectiva docente: cómo funcionan las escuelas en las cárceles catalanas. Algunas conclusiones de un estudio de campo. 2.3.1. Funcionamiento diario. 2.3.2. Particularidades derivadas del encaje de la escuela en el medio penitenciario. A) El espacio físico que ocupa la escuela dentro de la prisión. B) La trascendencia de lo que ocurre en el aula. C) La relación entre la escuela y el régimen penitenciario. D) La relación entre la escuela y el tratamiento penitenciario. IV. UNA SERIE DE CONSIDERACIONES ACERCA DEL ENCAJE DE LAS ESCUELAS EN LAS CÁRCELES CATALANAS. 1. La incardinación de las escuelas en el sistema penitenciario. 2. El derecho a la educación y la reeducación y reinserción social. 3. Los límites (sombras) y las posibilidades (luces) educativas en los contextos de encierro. V. BIBLIOGRAFÍA.
\end{abstract}

\title{
I. EL EJERCICIO DE DERECHOS FUNDAMENTALES EN LA CÁRCEL
}

Las cárceles del Estado español albergan a personas que tienen legalmente privada su libertad ambulatoria. Es solo el derecho a la libertad ambulatoria el que es objeto de dicha privación. Y esto es así por imperativo constitucional, ya que el art. 25.2 CE señala que las personas condenadas que estén cumpliendo una pena de prisión gozarán de los derechos fundamentales «a excepción de los que se vean expresamente limitados por el fallo condenatorio, el sentido de la pena y la ley penitenciaria». Esta idea se refuerza desde el ámbito internacional, pues la jurisprudencia del Tribunal Europeo de Derechos Humanos (TEDH) afirma que, con carácter general, las personas privadas de libertad siguen disfrutando de todos los derechos del Convenio Europeo de Derechos Humanos (CEDH), salvo el derecho a la libertad ambulatoria (Blanco Cordero 2018, 269).

Los tres elementos a los que se hace referencia como fuentes de excepción en el ejercicio de derechos fundamentales - el fallo condenatorio, el sentido de la pena y la ley penitenciaria- deben ser, sin duda, interpretados a la luz de los principios constitucionales y penales básicos, comenzando por el principio de legalidad penal y la reserva de ley.

La interpretación del contenido del fallo no plantea muchos problemas. Sin embargo, sí resulta más peliagudo interpretar el sentido de la pena y la 
ley penitenciaria. Respecto de la ley penitenciaria, si bien la privación de libertad se encuentra regulada por la Ley Orgánica General Penitenciaria (LOGP), esta norma no regula todos los extremos de tal privación y deja amplios espacios de indeterminación que se cubren por normas de rango legal inferior, que hacen cuestionable el respeto a la reserva de ley - cuando reglamentariamente se regulan cuestiones que afectan a derechos fundamentales - e incluso, al principio de legalidad penal — cuando directamente son normas administrativas las que restringen derechos fundamentales-. Esto demuestra que «el desarrollo legislativo puede encargarse de vaciar de contenido las grandes declaraciones de derechos» (Benito López 2007, 82). Con respecto al sentido de la pena, hay quienes sostienen que se refiere a que la propia pena implica una serie de limitaciones de otros derechos que son inevitables, y otros señalan que se refiere a la orientación resocializadora de la privación de libertad — de acuerdo con una interpretación sistemática de los apartados del art. $25 \mathrm{CE}$-. En cualquier caso, existe un riesgo de utilizar este elemento «como un cajón de sastre, para poder limitar en exceso otros derechos del recluso» (Benito López 2007, 79), de manera que debe reivindicarse una interpretación respetuosa y adecuada al principio de legalidad, la cual «tendría efectos prácticos fundamentales para el estatus jurídico de los internos» (Solar Calvo 2019, 783).

Por tanto, en sede constitucional - si bien se reconocen excepciones al ejercicio de derechos fundamentales-, las personas privadas de libertad tienen reconocido formalmente el pleno ejercicio de sus derechos; $y$, cualquier limitación, debe leerse en términos excepcionales y siempre respetando el principio de legalidad penal.

Sin embargo, las previsiones constitucionales y su interpretación conjunta pierden fuerza conforme se desciende por el entramado normativo, evidenciándose una «devaluación» de los derechos fundamentales de las personas privadas de libertad ya en la normativa penitenciaria de más alto rango legal, y acentuándose y consolidándose esta en la práctica penitenciaria (Rivera Beiras 1997, 386-387). Existen distintos elementos que contribuyen a dicha devaluación. Nos referiremos brevemente a uno de los más relevantes: la aún utilizada doctrina de las relaciones de sujeción especial.

La doctrina de las relaciones de sujeción especial es «una construcción jurídica que fundamenta un debilitamiento o minoración de los derechos de los ciudadanos, o de los sistemas institucionalmente previstos para su garantía, como consecuencia de una relación cualificada con los poderes públicos» (Lasagabaster 1994, 25). Su origen está basado en la consideración de que existe un espacio de la actividad estatal no sometido a control jurídico (Mapelli Caffarena 1992, 291). Esta doctrina legitima la excepción a la vigencia general de los principios y garantías jurídicas que protegen derechos 
fundamentales, generando dos estatus: el general y el «disminuido» (Lasagabaster 1994, 419).

La aplicación de esta doctrina a la privación de libertad se ha consolidado jurisprudencialmente, de manera que la relación jurídica penitenciaria es considerada una relación de sujeción especial. Parte de la doctrina penalista se muestra a favor del uso de esta doctrina en el ámbito penitenciario. Sin embargo, también existen muchos autores y autoras que critican su aplicación y consideran que no es admisible. Las críticas señalan, por un lado, que no encaja con nuestro modelo constitucional de Estado, sino que se corresponde con una «concepción absoluta del Estado» (Mapelli Caffarena 1992, 325) y una «concepción de la actividad administrativa al margen del sometimiento al Derecho» (Tamarit Sumalla et al. 2005, 77). Por otro lado, se critican sus efectos de relajación de la reserva de ley y del principio de legalidad (Mata y Martín 2011, 150), que tienen como consecuencia una indefinición en las posibilidades de limitación de derechos fundamentales por parte de la Administración, de manera que se coloca a las personas privadas de libertad en una situación de «absoluta indefensión» (Mapelli Caffarena 1992, 325). En definitiva, se advierte que la aplicación de esta doctrina supone la vulneración de plano de las normas penales y constitucionales. E incluso, el respaldo de la existencia de «un ciudadano de segunda categoría, titular de unos derechos devaluados, que pone en entredicho la vigencia efectiva de la garantía ejecutiva que se deriva del principio de legalidad» (Rivera Beiras 1997, 369).

El rechazo de esta doctrina no pretende obviar que, de facto, la propia privación de libertad en una institución como la cárcel, efectivamente, genera otras restricciones y/o privaciones de derechos fundamentales (Martínez Escamilla 1998, 253). Sin embargo, admitir esta realidad penitenciaria no debe equipararse a la aceptación de una doctrina que lo que hace es validar jurídicamente un supuesto de hecho inadmisible — por ser vulnerador de derechos fundamentales - , pretendiendo convertirlo en legítimo y pacífico (Benito López 2017, 86). Como acertadamente señala Solar Calvo, «el concepto de relación de sujeción especial sigue justificando la situación jurídica diferenciada que de facto se produce» $(2019,799)$. Por tanto, el abordaje es más complejo de lo que a priori pueda parecer y, en esta complejidad, es necesario distinguir — una vez más- el ser del deber ser.

A pesar de estas críticas, lo cierto es que la jurisprudencia del Tribunal Constitucional continúa calificando la relación penitenciaria como una relación de sujeción especial, haciendo referencia a la retahíla de sentencias que consolidaron esta consideración constitucional ${ }^{1}$. Sin embargo

${ }^{1}$ Las SSTC 2/1987, de 21 de enero y 120/1990, de 27 de junio, entre otras, avalan la doctrina de la relación de sujeción especial en el sistema penitenciario. En la STC 2/1987, 
—aun siendo así-, en los últimos años, se han dictado importantes sentencias que han otorgado el amparo a personas presas por vulneración de sus derechos fundamentales. Dos de ellas - dictadas en fechas muy próximas - fueron la STC 6/2020, de 27 de enero, y la STC 18/2020, de 10 de febrero. En estas sentencias, se sigue afirmando que la persona privada de libertad se encuentra en una relación de sujeción especial, pero de ello el TC no deriva una validación del supuesto de hecho en el que un derecho fundamental se ha visto restringido. Se puede inferir que se habla de relación de sujeción especial en un sentido más descriptivo que prescriptivo, y, en cualquier caso, siempre respetuoso del principio de legalidad penal y la reserva de ley (FJ 3.A.b, STC 6/2020). Es decir, se establece que dicha relación «debe ser entendida en un sentido reductivo compatible con el valor preferente de los derechos fundamentales» (FJ 5.a, STC 18/2020), que deben actuar «como límites infranqueables de la actuación de la administración penitenciaria» (FJ 5.d, STC 18/2020). A partir de aquí, en ambas sentencias, se hace un análisis riguroso de la posible vulneración de derechos fundamentales, realizando una ponderación garantista y exigiendo que las limitaciones de derechos fundamentales sean siempre motivadas y proporcionadas, «porque constituye el único medio para constatar que la ya limitada esfera jurídica del ciudadano interno en un centro penitenciario, no se restringe o menoscaba de forma innecesaria, inadecuada o excesiva» (FJ 3.B, STC 6/2020). Al final, en ambos casos, se reconoce la vulneración del derecho fundamental a la libertad de expresión.

Nuestro posicionamiento, junto al de gran parte de la doctrina penalista, es contrario al uso de doctrinas como la de las relaciones de sujeción especial para justificar las restricciones en el ejercicio de derechos fundamentales. No obstante, como decíamos, también advertimos que la privación de libertad constituye, de facto, una situación limitativa que impide el pleno ejercicio del resto de derechos fundamentales; e incluso, que el espacio carcelario puede calificarse como «zona de no derecho» o «espacio ajeno al derecho» (Rivera Beiras 1997, 392).

se explica el fundamento de la sujeción especial: "El interno se integra en una institución preexistente y que proyecta su «autoridad» sobre quienes, al margen de su condición común de ciudadanos, adquieren el status especifico de individuos sujetos a un poder público que no es el que, con carácter general, existe sobre el común de los ciudadanos." Asimismo, las SSTC 119/1996, 175/2000 y 140/2002 señalan que existe una sujeción especial porque la persona presa se integra en "una institución preexistente que proyecta su autoridad sobre quienes ingresan en ella", y lo hace para salvaguardar la seguridad y el orden regimental, de manera que la persona debe acatar las normas de régimen interior que se consideren necesarias. Con ello, se admite la limitación de derechos fundamentales (SSTC 35/1996 y 207/1996), y se reconoce que el principio de legalidad "pierde parte de su fundamentación material" (STC 2/1987). 
Partiendo de este panorama, consideramos importante analizar en profundidad, desde una perspectiva crítica y con rigor, cuál es el grado de reconocimiento efectivo de los derechos fundamentales durante la ejecución. Para ello, es necesario descender a través de los distintos instrumentos normativos que regulan lo penitenciario y, también, tratar de aproximarse a la praxis penitenciaria.

A continuación, abordamos esta tarea y, para ello, elegimos analizar el ejercicio del derecho a la educación. Son varios los motivos por los que decidimos analizar este derecho fundamental. En primer lugar, evidentemente, porque, al tratarse de un derecho fundamental, es uno de aquellos derechos que, en principio, las personas privadas de libertad deberían estar en iguales condiciones de ejercer que las personas que viven en libertad. En segundo lugar, por la centralidad de la educación en la sociedad, ya que se trata de una actividad muy valorada y con una trascendencia muy importante, tanto en las vidas particulares de todas las personas como a nivel colectivo. En tercer lugar - y sobre todo-, porque, concretamente, el ejercicio del derecho a la educación en la cárcel ha sido escasamente tratado desde el ámbito jurídico $y$, sin embargo, en torno a él existe una particular problemática que es interesante conocer: cómo se relaciona la actividad educativa con el tratamiento penitenciario; $y$, en caso de considerar la educación parte del tratamiento: cómo se traslada a la actividad educativa la cuestión de la voluntariedad. Y, finalmente, porque contamos con un conocimiento directo de parte de la realidad de la actividad educativa en las cárceles catalanas, lo que nos ha permitido identificar las problemáticas que abordamos en este artículo.

\section{LA EDUCACIÓN COMO DERECHO HUMANO Y DERECHO FUNDAMENTAL}

La educación constituye una actividad central en nuestras sociedades y, desde el punto de vista jurídico, de acuerdo con las normas nacionales e internacionales, es un derecho fundamental y humano.

En el ámbito internacional, la educación es un derecho humano reconocido a toda persona en el art. 26 de la Declaración Universal de los Derechos Humanos (DUDH), que atribuye a la educación el objetivo del «pleno desarrollo de la personalidad humana y el fortalecimiento del respeto a los derechos humanos y a las libertades fundamentales». Junto a esta previsión normativa, es importante destacar que Naciones Unidas señala como Objetivo de Desarrollo Sostenible (ODS) n..$^{\circ}$ 4: «Garantizar una educación inclusiva, equitativa y de calidad y promover oportunidades de aprendizaje durante toda la vida para todos». El art. $2 \mathrm{CEDH}$ señala que «A nadie se le puede negar el derecho a la educación». Y, finalmente, el art. 14 de la Carta de los Derechos Fundamentales de la Unión Europea (CDFUE) establece que 
«Toda persona tiene derecho a la educación y al acceso a la formación profesional y permanente».

En el ámbito del Estado español, la educación es un derecho fundamental reconocido a todas las personas en el art. $27 \mathrm{CE}$ y al que se atribuye el objetivo del «pleno desarrollo de la personalidad humana en el respeto a los principios democráticos de convivencia y a los derechos y libertades fundamentales». Dada su consideración de derecho fundamental, su desarrollo se realiza a través de ley orgánica, la Ley Orgánica de Educación. Además, el mismo texto constitucional, en su art. 10.2, establece que las normas relativas a los derechos fundamentales y a las libertades que la Constitución reconoce se interpretarán de conformidad con la DUDH y los tratados y acuerdos internacionales sobre las mismas materias ratificados por España, de manera que el derecho fundamental a la educación deberá interpretarse de acuerdo con la normativa internacional mencionada antes. Y, por último, es fundamental tener en cuenta que, de acuerdo con el art. 53.2 CE, el derecho a la educación cuenta con la especial protección derivada de la posibilidad de amparo constitucional.

Teniendo en cuenta que el objeto de este texto es, específicamente, el análisis de la educación en prisión, de la lectura de esta normativa cabe extraer dos consideraciones fundamentales acerca de la educación. Primera: que se trata de un derecho humano y fundamental que se reconoce a toda persona a lo largo de toda la vida. Segunda: que el objetivo fundamental de la educación es el pleno desarrollo de la personalidad y el respeto a los derechos y libertades fundamentales. En este sentido, el TC español señala «la inequívoca vinculación del derecho a la educación con la garantía de la dignidad humana, dada la innegable trascendencia que aquélla adquiere para el pleno y libre desarrollo de la personalidad» (FJ 8, STC 236/2007, de 7 de noviembre).

\section{El objetivo del pleno desarrollo de la personalidad}

El objetivo del pleno desarrollo de la personalidad se atribuye a la educación, tanto en la DUDH como en nuestra Constitución. Se trata de un concepto jurídico que requiere de su interpretación para poder determinar cuáles son las consecuencias de la atribución de esta finalidad. En este sentido, se exponen a continuación algunas notas para su interpretación.

En primer lugar, el libre desarrollo de la personalidad «significa que el sujeto tiene capacidad para decidir por sí mismo sin interferencias ajenas en todas aquellas cuestiones que afectan directamente a lo que constituye su esfera de intereses» (Santana Ramos 2014, 103). Si bien es cierto que en los textos normativos mencionados se utiliza el concepto del pleno desarrollo de la personalidad - que pareciera hacer referencia a un determinado modelo ideal de personalidad alcanzable plenamente-, se entiende que pleno y libre desarrollo de la personalidad son términos equivalentes, y que la idea de 
plenitud de desarrollo personal remite precisamente al «ejercicio de la libertad individual» (Santana Ramos 2014, 104).

En segundo lugar, se considera que el libre desarrollo de la personalidad tiene una proyección tanto en la esfera externa de la persona como en su esfera interna. Asimismo, genera, por un lado, un derecho negativo, que implica una obligación de no injerencia a terceros, incluido el propio Estado; y un derecho positivo, que consiste en una obligación de apoyo o promoción (Kyszard Kosmider 2018, 670), que podría identificarse con la garantía del acceso a la educación. En este sentido, el TC español señaló que el derecho a la educación incorpora «junto a su contenido primario de derecho de libertad, una dimensión prestacional, en cuya virtud los poderes públicos habrán de procurar la efectividad de tal derecho» (STC 86/1985, de 10 de julio, FJ, $3^{\circ}$ ).

En tercer lugar, el libre desarrollo de la personalidad se encuentra estrechamente relacionado con el principio de dignidad humana, recogiéndose ambos en el art. 10.1 CE, y también con la autonomía individual para desarrollar un propio proyecto de vida (Kyszard Kosmider 2018, 698).

Finalmente, es fundamental tener en cuenta que esta autonomía con la que se relaciona el libre desarrollo de la personalidad se materializa en un contexto sociocultural concreto. Por tanto, aunque no se trate de un desarrollo hacia un determinado modelo ideal, no se puede obviar que este desarrollo de la personalidad libre estará inevitablemente afectado por los condicionantes socioculturales del lugar y el tiempo en el que se viva (Santana Ramos 2014, 107). En este sentido, la obligación de promoción a la que se hacía referencia antes implica la implementación de políticas públicas - entre ellas, las educativas - que reduzcan los condicionantes socioculturales que impiden a parte de la sociedad acceder a determinadas opciones de desarrollo personal y colectivo.

\section{EL EJERCICIO DEL DERECHO A LA EDUCACIÓN EN LAS CÁRCELES CATALANAS}

Partiendo del reconocimiento de la educación como un derecho humano y fundamental cuyo objetivo principal es el pleno desarrollo de la personalidad, revisamos el ejercicio del derecho a la educación de las personas privadas de libertad en las cárceles catalanas. La idea es tratar de determinar si el derecho a la educación se ve afectado de alguna manera en este contexto.

\section{La educación de personas privadas de libertad. Marco normativo de la educación en prisión}

En el ámbito internacional, las previsiones normativas sobre la educación de personas privadas de libertad, se encuentra en las Reglas Minimas de las 
Naciones Unidas para el Tratamiento de los Reclusos, en el Conjunto de Principios para la protección de todas las personas sometidas a cualquier forma de detención o prisión, y en las Reglas Penitenciarias Europeas. Se exige la garantía del acceso a la educación de las personas analfabetas, jóvenes o sin formación básica, la necesidad de conectar la educación dentro de las prisiones con los sistemas educativos públicos de cada país, y la relación con el tratamiento penitenciario. Por otro lado, cabe destacar la Resolución 1990/20 del Comité Económico y Social Europeo y la Declaración de Hamburgo de la UNESCO que advierten la importancia de la educación dentro de las prisiones como elemento esencial para el desarrollo de las personas, instándose a las Administraciones a hacer todo lo posible para garantizar este derecho.

Situándonos en el ámbito estatal, corresponde tener en cuenta, en primer lugar, las previsiones constitucionales que afectan al ejercicio del derecho a la educación en la cárcel — sin olvidar aquellas que se refieren a la educación en general, que ya hemos recogido en el apartado anterior-. Se trata del art. 25.2 CE. En este precepto constitucional se prevé, por un lado, lo que ya hemos abordado al principio de este trabajo: que los derechos fundamentales no restringidos legalmente - entre ellos, el derecho a la educación - deben poder ejercerse de igual manera dentro y fuera de prisión (pudiendo alcanzarse con ellos iguales objetivos). Por otro lado, se hace inevitable advertir que, en este mismo apartado del art. 25, también se encuentra la previsión que señala que las penas privativas de libertad «estarán orientadas hacia la reeducación y la reinserción social», y esta mención parece tener algo que ver con el tema que estamos tratando. Nosotros sostenemos que el ejercicio del derecho a la educación y el fin de la reeducación y la reinserción no son identificables. Puede quizás establecerse una relación entre ambos, pero consideramos fundamental apreciar las diferencias (y salvar las distancias). Abordaremos esta cuestión más adelante. De momento, procede analizar si esta declaración constitucional de igual ejercicio del derecho a la educación se mantiene en el desarrollo normativo y en la práctica.

A continuación, se encuentran las dos normas fundamentales que regulan lo penitenciario: la LOGP y el Reglamento Penitenciario (RP). Ambas establecen que la actividad penitenciaria, tanto de régimen como de tratamiento, deberá desarrollarse respetando la personalidad del sujeto y los derechos civiles, políticos, sociales, económicos y culturales no afectados por la condena. Sin embargo, respecto de los deberes de quienes están en prisión, mientras la LOGP no prevé la obligación de participar en actividades educativas - como en cambio sí se prevé en el caso del trabajo, que se considera tanto un derecho como un deber-, el RP establece que la persona presa deberá «Participar en las actividades formativas, educativas y laborales definidas en función de sus carencias para la preparación de la vida en libertad» (art. 5.2, párrafo g) RP). 
En cuanto a los apartados específicos que tratan el aspecto educativo, por un lado, en la LOGP, se encuentra el Capítulo X, denominado Instrucción y educación. En él se indica que: 1) Debe existir una escuela en cada prisión. 2) La Administración penitenciaria fomentará el interés por el estudio y facilitará la participación de las personas presas, especialmente de jóvenes y analfabetas. 3) Se dará la posibilidad de obtener titulaciones oficiales y acceso a formación universitaria mediante convenios.

Por su parte, en el RP, el Capítulo III, denominado Formación, cultura y deporte, se prevé que: 1) Las actividades educativas se agrupan junto con las formativas, culturales y deportivas, y todas ellas estarán determinadas por el Consejo de Dirección de la prisión, de acuerdo con el tratamiento penitenciario. 2) Todas estas actividades se incentivarán mediante recompensas y beneficios penitenciarios. 3) Las personas que ingresen sin la formación básica obligatoria tendrán la obligación de acudir a la escuela, priorizando a personas analfabetas, jóvenes y extranjeras. 4) Si la actividad educativa implica modificaciones regimentales, deberá estar autorizada por la Dirección, y podrá denegarse por motivos de seguridad. 5) En todas las prisiones existirá una o varias Unidades Educativas.

Tras analizar las dos normas anteriores, se evidencia que, mientras la LOGP prevé la actividad educativa en prisión sin considerarla un deber de la persona privada de libertad y sin establecer ninguna relación con el tratamiento penitenciario, el RP sí la considera un deber y la coloca directamente como un elemento que forma parte del tratamiento. De hecho, en el RP, el Capítulo que regula la actividad educativa se encuentra contenido en el Título Del tratamiento penitenciario, mientras en la LOGP, está en un Título aparte (Del régimen penitenciario).

Dado que el RP es una norma posterior a la LOGP que sirve para desarrollar esta última y concretarla, aunque se produzca esta diferencia, es difícil sostener que esto las haga contradictorias. Incluso se considera que, en realidad, lo que sucede es que el RP de 1996 adopta un «concepto de tratamiento inclusivo», que permite incorporar la actividad educativa «en la consecución de la finalidad resocializadora» (Rodríguez Yagüe 2012, 69).

No obstante, para analizar e interpretar correctamente la normativa en vigor, es necesario tener en cuenta otra norma posterior: el Real Decreto 1203/1999, que supuso la inclusión de los maestros y maestras y de las normas de funcionamiento de las escuelas de prisiones en el ámbito competencial de los departamentos de educación de cada Comunidad Autónoma. Esta norma es consecuencia de la Ley Orgánica 1/1990, de 3 de octubre, de Ordenación General del Sistema Educativo (LOGSE) que ordenaba «normalizar la educación en el ámbito penitenciario incardinándola en el sistema educativo general y situándola bajo la responsabilidad de la Administración educativa competente». Se trata de una norma de igual rango que el RP, de 
aprobación posterior y con un mayor grado de especialidad, de manera que, en caso de contradicción, deroga lo previsto por el RP. En este sentido, deroga expresamente los preceptos donde se prevé que el personal docente sea parte de la Junta de Tratamiento (JT) o de los Equipos, modificándose en consecuencia el RP. No obstante, desde nuestro punto de vista, cabe interpretar que, de facto, también quedan derogadas otras previsiones del RP.

Esta norma establece que la responsabilidad de la educación en las prisiones ya no es de la Administración penitenciaria, sino de la Administración educativa competente. En consecuencia, se señala que las funciones de la Administración penitenciaria en relación con la actividad educativa se limitan a: la puesta a disposición de las instalaciones necesarias dentro de la prisión, el aseguramiento de una dotación económica anual para financiar los gastos de funcionamiento, y la realización de las otras actividades que ya venía realizando junto a la educativa (culturales, ocupacionales y deportivas). En este sentido, cabe afirmar que también el art. 118 RP queda derogado, al menos parcialmente, pues las actividades educativas no vendrán definidas por la Dirección de la prisión. En cualquier caso, se señala que el personal docente deberá respetar las normas de control y seguridad, que la actividad educativa deberá adaptarse a los horarios de la prisión, que se trasladará información de los resultados del proceso educativo, y que, entre las dos Administraciones (penitenciaria y educativa), que ahora comparten espacio, deberá establecerse una relación de coordinación (no de subordinación).

Consideramos que esta norma produce una modificación radical en relación con la incardinación de la actividad educativa en las prisiones, ya que se incorpora la Administración educativa, que será la única competente para el desarrollo de esta actividad. De ello se desprende la pretensión de trasladar la competencia del funcionamiento y la organización de las escuelas de las prisiones a los responsables educativos de cada territorio, con el objetivo de apartarla de las disposiciones penitenciarias, ya sean de régimen o de tratamiento, reconociendo su entidad propia y consecuente y necesaria autonomía con respecto al funcionamiento penitenciario. Desde nuestro punto de vista, es posible afirmar que, con ello, todas las previsiones que incardinan la actividad educativa en el ámbito de la ejecución penitenciaria deben entenderse derogadas de facto.

Sin embargo, esta norma también contiene otra previsión muy importante: la Disposición final primera que señala respecto del articulado que, mientras los arts. 1 a 5 tienen carácter de norma básica y rigen en todo el territorio español, los arts. 6 a 11 no son de aplicación en las Comunidades Autónomas que ejerzan competencias de ejecución de la legislación penitenciaria estatal. Este es el caso de Catalunya. 


\section{La actividad educativa en las cárceles catalanas}

Una vez analizada la normativa española en relación con el derecho a la educación en las cárceles, nos situamos ahora en el territorio catalán donde — si bien es de aplicación toda la normativa anterior-, desde 1983, la competencia penitenciaria para ejecutar las penas se encuentra transferida a la Generalitat de Catalunya y, para llevar a cabo esta ejecución, la Administración catalana genera su propia normativa en materia penitenciaria.

En relación con las escuelas, en Catalunya inicialmente, los maestros y maestras de las prisiones eran personal del Departament de Justícia. Como se ha visto, esto cambió en 1999, y, con el Decret 325/2006, se estableció que la titularidad y la dirección de los centros educativos en las cárceles catalanas pertenecía al Departament d'Educació.

También en el año 2006, se aprobó el Decret 329/2006, que es la norma que desarrolla el RP catalán (RPCat): establece la organización y el funcionamiento de la ejecución penal en Catalunya. Los aspectos destacables de esta norma en relación con la actividad educativa son los siguientes: 1) El RPCat se divide en Títulos, de manera que el Título IV regula los servicios propios de la Administración penitenciaria, distinguiendo tres ámbitos de actuación: administrativo, de rehabilitación y de régimen interior; y, por otro lado, en el Título V, se regulan las prestaciones de la Administración —en general, no la penitenciaria-: asistencia sanitaria, educación y servicios sociales. 2) En el Capítulo II del Título V, se regula la educación en los centros penitenciarios. Primero: se determina cuál es el papel de la Administración penitenciaria en relación con la educación: «debe velar por que las personas ingresadas en establecimientos penitenciarios tengan acceso a las enseñanzas que les correspondan de acuerdo con el grado de instrucción y las necesidades educativas que presenten, y en especial, los/as analfabetos/as, los/as jóvenes y los/as extranjeros/as» (art. 90.3), y tiene como obligaciones específicas en este ámbito el ofrecimiento de las instalaciones y hacerse cargo de las otras actividades que antes se encontraban agrupadas con la educativa. Segundo: se contienen varias previsiones en las que se hace referencia a la coordinación entre el departamento competente en ejecución penal y el departamento competente en educación: ambos deben garantizar el acceso a la educación, el servicio educativo debe ajustarse a la organización interna de la prisión y, finalmente, el/la Directora/a docente y el/la Subdirector/a de Tratamiento intercambiarán información, y la primera participará en el Consejo de Dirección cuando se traten cuestiones en materia educativa. Tercero: respecto del personal docente se prevé: «Durante el curso académico, se integrará en los órganos colegiados del centro penitenciario con la finalidad de favorecer la incardinación de la programación educativa en la general del establecimiento para la mejor consecución de las políticas penitenciarias de 
reeducación y reinserción» (art. 94.2). 3) En el Título III, donde se regula la organización de los centros penitenciarios, se prevé que el/la Director/a docente formará parte de la JT, aunque entre las funciones de este órgano no se menciona en ningún momento el ámbito educativo; y también se prevé que un/a docente formará parte del Equipo Multidisciplinario (EMD), aunque tampoco se mencionen funciones concretas de este órgano en el ámbito educativo.

Observamos que, mientras se produce una separación entre el ámbito de la ejecución penal y el educativo - dependiendo cada uno de Administraciones diferentes y encomendando a la Administración penitenciaria una mera labor de facilitación y garantía, y no de realización directa-, al mismo tiempo, el RPCat establece la presencia del personal docente en la JT y los EMD. No entendemos esta inclusión, y no la encontramos coherente con el resto de las previsiones normativas. En cualquier caso, antes de exponer nuestras valoraciones al respecto, corresponde continuar explicando cuáles son los elementos de la ejecución que interfieren en el funcionamiento de la escuela en las prisiones catalanas.

\subsection{Sistema de Evaluación y Motivación $\left(\mathrm{SAM}^{2}\right)$}

El SAM es un instrumento regulado por la Circular 1/1999, de 22 de enero, de la Direcció General de Serveis Penitenciaris i Rehabilitació, cuyo objetivo es establecer un sistema de motivación para las personas privadas de libertad. Esta herramienta motivacional consiste en que, a partir de una evaluación de tres áreas (actividades, conducta y salidas), se clasifica a la persona en cuatro niveles (A, B, C, D). En función del nivel, es posible conseguir ciertas recompensas (comunicaciones especiales o notas meritorias) y beneficios penitenciarios (adelantamiento de la libertad condicional o indulto particular).

En el SAM se introducen las actividades que se considera que deben evaluarse desde el punto de vista del tratamiento penitenciario y ver su evolución. Dentro de las actividades, puede incluirse la asistencia a la escuela. Así, una de las valoraciones que influyen en esta evaluación motivacional es la que hace el personal docente sobre el desempeño de la persona presa en la escuela. En caso de buena actitud y participación, los «puntos» de la escuela ayudarán a la persona a acercarse a las letras $\mathrm{A} / \mathrm{B}$, mientras que, si la evaluación es negativa, la nota final bajará.

Además, se puede decidir marcar alguna actividad (o varias) como «Principal». La valoración de estas actividades tiene una mayor influencia en el

${ }^{2}$ La sigla SAM se construye por su denominación en catalán: Sistema d'Avaluació $i$ Motivació. 
resultado del SAM que la de aquellas que no se marcan así. Hasta el punto de que, si una actividad marcada como «Principal» se abandona, es posible marcarla como «Principal no hecha»y, entonces, el resultado del SAM es una «D» automática en ese periodo de evaluación trimestral, independientemente de su desempeño en otras actividades. Además, el SAM llega al absurdo de perjudicar, con la «D» automática a la persona que empieza la actividad y posteriormente la deja, pero, en cambio, puede no perjudicar a quien directamente no empieza la actividad. Se penaliza más, pues, a quien al menos ha hecho el esfuerzo de intentarlo que a quien no.

\subsection{Programa Individualizado de Tratamiento (PIT)}

El PIT es el instrumento central que planifica y orienta la observación y evaluación de las personas privadas de libertad, así como los objetivos de tratamiento que decidan los/as respectivos/as profesionales. El PIT es un contrato entre la Administración penitenciaria y la persona presa, por el que esta se compromete a cumplir con una serie de propuestas de tratamiento que la institución considera que debe realizar para poder evolucionar positivamente. Entre ellas, puede incluirse: reconocer el delito, satisfacer la responsabilidad civil, adquirir hábitos laborales, llevar a cabo los programas de rehabilitación en función del delito y circunstancias personales, etc. En principio, la persona presa puede aceptar o no el tratamiento, pues este, en principio, no es obligatorio. Sin embargo, en la práctica, si no se cumple con el itinerario tratamental propuesto, desaparece la posibilidad de acceder a permisos o progresar en grado, de manera que esa voluntariedad se ve fuertemente condicionada.

Existe la posibilidad de que uno de los requisitos del PIT sea, precisamente, la obligación de acudir a la escuela; exigencia habitual en el caso de personas jóvenes sin una formación básica. Si bien es cierto que no se puede negar que acudir a la escuela puede tener efectos muy positivos en todos los casos - y más aún en el caso de personas jóvenes sin formación-, creemos que puede resultar cuestionable que la decisión de una persona adulta sobre el ejercicio de un derecho fundamental pueda tener efectos en su grado de privación de libertad, porque pueda condicionar, en alguna medida, la concesión de permisos o del tercer grado.

\subsection{Perspectiva docente: cómo funcionan las escuelas en las cárceles} catalanas. Algunas conclusiones de un estudio de campo

El segundo autor de este artículo es maestro en un centro penitenciario catalán y es por este motivo por el que conoce de primera mano esta realidad y su funcionamiento. Además, el año pasado elaboró un trabajo de investigación 
titulado Escola i presó a Catalunya. Una radiografia del dret a l'educació a les presons catalanes, que le permitió realizar un estudio sobre la materialización del derecho a la educación en el medio penitenciario a través de encuestas realizadas a personal docente de escuelas de distintas cárceles $(7$ directores/as docentes y 60 maestros/as), además de mostrar sus propios conocimientos y consideraciones al respecto. El objetivo de este estudio era recoger las experiencias y opiniones del personal docente sobre su labor para obtener una visión de la situación de las escuelas en las cárceles catalanas y detectar las posibles problemáticas existentes ${ }^{3}$. En este apartado, con el objetivo de realizar una aproximación al funcionamiento de las escuelas dentro de las cárceles catalanas, recogemos consideraciones extraídas del estudio mencionado y también algunas propias derivadas de la experiencia directa del autor.

\subsubsection{Funcionamiento diario}

El funcionamiento de las escuelas dentro de las prisiones catalanas es, en principio, igual que el de cualquier centro educativo del sistema público, dado que, como ya se ha visto, forman parte de la red pública y dependen del Departament d'Educació. En este sentido, debe destacarse que, a pesar de las diferencias que a continuación señalaremos, la Generalitat ha dotado sus prisiones de verdaderas escuelas de personas adultas, cuyas características de partida no las diferencian de las que existen fuera (amplia oferta formativa adaptada a las necesidades e impartición de clases por materias y niveles), y esto es un gran avance y una gran diferencia entre las prisiones catalanas y las del resto del Estado.

Una diferencia que sí puede advertirse respecto del resto del sistema de educación pública es la forma en la que se entra en contacto con el centro educativo. Cuando una persona ingresa en prisión, un miembro del equipo docente se pone en contacto con ella para realizar una entrevista inicial (práctica que tiene lugar en todos los centros, según el estudio realizado). Esta entrevista permite que la persona que ingresa conozca la existencia de la escuela, y esto puede propiciar un interés en participar en ella. A pesar de esta iniciativa, la mayoría del personal docente sostiene que el absentismo escolar es una de las principales problemáticas de las escuelas. Para paliarlo, se requerirá un trabajo pedagógico, sin duda costoso, pero necesario, que acabará beneficiando tanto al sujeto como la comunidad (Gil Cantero 2010, 53). Por otro lado, la entrevista inicial será el momento que podrá servir para determinar el nivel educativo de la persona, lo que, en algunas escuelas, da lugar a la inclusión en el PIT de la obligación de acudir a la escuela.

${ }^{3}$ Queda pendiente completar este estudio con la incorporación de la perspectiva del alumnado, que no ha podido realizarse todavía por las complejidades propias de su situación de privación de libertad sumadas a las circunstancias actuales en relación con la Covid-19. 
Tras la entrevista inicial, el contacto del personal docente y el alumnado se produce tanto en las clases que se imparten en la escuela como en los espacios de tutorías. Las tutorías son espacios individuales que sirven para realizar un seguimiento y acompañamiento escolar personalizado. El profesorado dispone de entre una y dos horas semanales para destinarlas a esta tarea, sin embargo, en las escuelas de las cárceles, frecuentemente, son espacios infrautilizados. Los motivos pueden ser variados. Sin embargo, consideramos que puede resultar altamente determinante el hecho de que el/la docente se encuentra integrada en un EMD que realiza la evaluación de la evolución del tratamiento penitenciario, a través de los instrumentos mencionados antes (SAM y PIT). En consecuencia, puede ocurrir que se renuncie a este espacio de seguimiento individual, única y específicamente educativo, y sin consecuencias en la ejecución de la pena.

\subsubsection{Particularidades derivadas del encaje de la escuela en el medio penitenciario}

\section{A) El espacio físico que ocupa la escuela dentro de la prisión}

En relación con el espacio físico escolar, las escuelas cuentan con un lugar específico en el que se desarrolla la actividad educativa. Es decir, la escuela es un espacio ubicado dentro de la prisión, pero diferenciado del resto de espacios. Es un lugar de encuentro, en el que las personas privadas de libertad que conviven separadas en distintos módulos se mezclan para las clases. En algunas escuelas, el espacio escolar resulta insuficiente y la tarea educativa se tiene que trasladar a otras dependencias penitenciarias. Este y otros condicionantes derivados de la gestión del centro penitenciario «pueden entorpecer la efectiva aplicación del derecho a la educación» (Ruiz Cabello y López-Riba 2019, 597). Tanto direcciones como personal docente destacan varias consecuencias negativas de ello, como, por ejemplo, la pérdida de la posibilidad de que la actividad educativa se pueda experimentar como algo ajeno a las lógicas penitenciarias. Casi la totalidad del personal docente encuestado en el estudio afirma que el alumnado le ha manifestado que en la escuela se siente tratado de manera diferente; hecho que demuestra que, efectivamente, la escuela es un espacio totalmente diferenciado del medio en que se encuentra (Cánovas Calatrava 2010,11). Asimismo, esto se refuerza por el hecho de que la escuela constituye un espacio de participación. Si tenemos en cuenta que las personas que viven en prisión no deciden casi absolutamente nada de su día a día (horarios, visitas, comidas, actividades...), los centros educativos destacan en este punto por disponer, todos ellos, de espacios de participación del alumnado. En este sentido, la escuela puede suponer el reflejo de otras maneras de actuar posibles (Blazich 2007, 57-58). 
B) La trascendencia de lo que ocurre en el aula

Todos los centros docentes cuentan con unas Normas de organización y funcionamiento del centro (NOFC), reguladas en la Llei d'Educació de Catalunya y en el Capítulo III del Decret 102/2010 de autonomía de centros educativos. Entre diferentes aspectos, las NOFC recogen «los mecanismos y fórmulas para la prevención y resolución de conflictos» (art. 23.2), así como las «garantías y procedimiento en la corrección de faltas gravemente perjudiciales para la convivencia» (art. 25). Pues bien, a pesar de que todos los centros escolares tienen NOFC propias, cuando por parte del alumnado se da alguna conducta contraria a la normativa del centro (escolar) que supone algún tipo de sanción, según el estudio, en la mitad de las escuelas, se remite siempre la información al EMD, mientras que, en la otra mitad, se remite según la gravedad de los hechos.

La remisión de esta información al centro penitenciario supone una expansión de las consecuencias de los actos del alumnado más allá del centro educativo, hecho que solo sucede en el ámbito penitenciario, puesto que, fuera de este, sería impensable que el comportamiento de un mayor de edad en un centro educativo - salvo que fuera un comportamiento delictivo - tuviera repercusiones en otras áreas de su vida. Así, las escuelas están desaprovechando la ocasión de actuar de manera diferente ante la aparición de conflictos, y, en definitiva, de «abrir un espacio con reglas de juego propias que permita la construcción de nuevas formas de subjetivación» (Blazich 2007, 57).

\section{C) La relación entre la escuela y el régimen penitenciario}

Respecto de la relación de la escuela con el régimen, es decir, con la seguridad y el orden en el centro penitenciario, todas las direcciones docentes y la mayoría del personal docente encuestado en el estudio, consideran que su tarea se ve limitada por motivos regimentales. La mayoría de los motivos se encuentran relacionados con los horarios - los cuales los marca la prisióny con la prohibición de utilizar ciertos materiales, Internet o de realizar ciertas actividades. Con ello, la institución educativa se ve obligada a claudicar ante la institución penitenciaria. Este es uno de los principales problemas de las escuelas de prisiones, y debe abordarse teniendo en cuenta «que la educación, tal como ocurre fuera de la prisión, tiene un papel muy relevante en la vida de las personas internas y en el propio ambiente de la institución» (Ruiz Cabello y López-Riba 2019, 598). Por ello, debe reivindicarse que:

La institución educativa es la responsable de la educación de los ciudadanos, con independencia del espacio social en que vivan, y debe ejercer su responsabilidad por encima del control del contexto del castigo. La prisión se debe adecuar a las necesidades de la acción educativa y no al contario (Viedma Rojas 2017, 104). 
D) La relación entre la escuela y el tratamiento penitenciario

Como ya se ha mencionado anteriormente, la participación en la escuela es habitualmente objeto de inclusión en el PIT y de evaluación en el SAM, lo que supone que, así, se introduce la actividad educativa como parte del tratamiento penitenciario. Según el estudio mencionado, la totalidad de las direcciones docentes considera que la escuela tiene que formar parte del tratamiento penitenciario. En el caso del personal docente encuestado, el porcentaje es menor, pero también se manifiesta mayoritariamente a favor de esta inclusión. No obstante, a pesar de este sentir general sobre la necesidad de que la escuela forme parte del tratamiento, se evidencia que no existe una misma comprensión sobre qué significa esto y qué consecuencias tiene. Ya que, como se muestra en el estudio, en cada escuela se entiende de manera dispar, según considere la dirección docente.

En primer lugar, en cuanto al SAM, según el estudio, todas las escuelas dan de alta/baja y valoran sus actividades desde el SAM; en casi todas, se marca como «Principal» alguna actividad educativa; y, en algunas, se marca como «Principal no hecha» cuando un/a alumno/a se da de baja de una actividad «Principal». Sin embargo, algunas direcciones docentes no conocen la consecuencia de la «D» automática.

En segundo lugar, en relación con el PIT, según el estudio, en todas las escuelas, hay actividades escolares que forman parte del PIT, mayoritariamente, los niveles más básicos. En algunos centros, el incumplimiento del área formativa del PIT es motivo de denegación de permisos y/o progresión a tercer grado. Finalmente, resulta llamativo que todas las personas encuestadas consideran que, al menos inicialmente, una parte del alumnado asiste a la escuela para cumplir el PIT, y no por voluntad propia.

\section{IV.UNA SERIE DE CONSIDERACIONES ACERCA DEL ENCAJE DE LAS ESCUELAS EN LAS CÁRCELES CATALANAS}

\section{La incardinación de las escuelas en el sistema penitenciario}

La existencia de escuelas dentro de las cárceles implica la ubicación de «una institución dentro de otra y supone conjugar prácticas y marcos normativos entre el sistema penitenciario y el sistema educativo con lógicas de funcionamiento diferentes» (Blazich 2007, 54). Las diferentes maneras de ligar la escuela con la institución penitenciaria dependerán de que la actividad educativa dentro de prisión se entienda como un elemento más del tratamiento penitenciario o, de lo contrario, como un derecho fundamental que la Administración tiene el deber de garantizar, pero no la potestad de imponer.

En la normativa y praxis penitenciaria de las cárceles catalanas, la escuela se conecta con el tratamiento penitenciario. Por un lado, la distribución 
competencial diferenciada de una y otra actividad contribuye a la separación de la escuela del aparato penitenciario en el que se encuentra ubicada. Sin embargo, a pesar de que las escuelas formen parte de la Administración educativa y no de la penitenciaria, la realidad es que su vínculo con la cárcel no se limita al espacio físico que ocupan y al alumnado al que atienden, sino que ambas se encuentran verdaderamente imbricadas. De acuerdo con el RPCat, las JT y los EMD constituyen órganos de la Administración penitenciaria que emiten resoluciones administrativas en materia de ejecución penal, de los que también forma parte personal docente que no pertenece a dicha Administración.

Esta configuración permite incardinar la actividad educativa en el tratamiento penitenciario, a pesar de la separación de partida. De esta forma, se incluye la actividad educativa en el SAM y el PIT, lo que afecta al funcionamiento de las escuelas en las prisiones. Sin embargo, lo que se observó en el estudio realizado por el segundo autor, es que esta afectación difiere en unas y otras escuelas: no se procede de la misma manera en relación con el uso de estos instrumentos y, en ocasiones, ni siquiera se conocen bien. Esto es un síntoma de que esta participación no resulta coherente, pues los maestros y maestras no son personal de tratamiento de la Administración penitenciaria, sino que son, simplemente, docentes. Y, en este sentido, resulta ilógico que participen en las decisiones sobre ejecución penitenciaria. De hecho, que la evaluación que hace un docente de su alumnado pueda tener afectaciones más allá del espacio-aula es, cuando menos, difícil de entender, y solo se explica por la incardinación de la escuela dentro de una «institución total» que afecta y condiciona todos los aspectos de la vida de las personas que la habitan (Goffman 2001, 17-20).

Consideramos que debería rechazarse de plano que los maestros y maestras sigan participando en los órganos que dirigen el tratamiento penitenciario, en coherencia con la separación institucional que existe entre el personal de tratamiento y el personal docente.

\section{El derecho a la educación y la reeducación y reinserción social}

Sostenemos que el derecho a la educación no se encuentra englobado en la orientación hacia de reeducación y reinserción social que se da a la privación de libertad. A pesar de la proximidad terminológica, no debe aceptarse su identificación con la actividad educativa - aunque esta se produzca en el contexto carcelario-, puesto que una y otra tienen consideraciones y niveles de protección diferentes y su vinculación puede tener consecuencias negativas.

Por un lado, el fin de reeducación y reinserción social, enunciado constitucionalmente, ha sido objeto de numerosas críticas y la política criminal de los últimos años ha mostrado el predominio de otros fines en sus propuestas. 
Además, se ha consolidado la consideración de la orientación de las penas privativas de libertad «hacia la reeducación y la reinserción social» como un mandato orientador, y no como un derecho subjetivo a la reinserción. Algunos autores y autoras reclaman el reconocimiento del derecho fundamental a la reinserción, interpretando el art. 25.2 CE «en el sentido marcado por el propio texto al que pertenece» (Solar Calvo 2019, 802) y teniendo en cuenta la jurisprudencia del TEDH que declara la existencia de este derecho, conectado con las obligaciones positivas del Estado para el respeto de la dignidad humana (art. 3 CEDH) (Blanco Cordero 2018, 281). Sin embargo, sigue sin reconocerse un derecho fundamental a la reinserción. En cualquier caso, a pesar de las críticas y de no considerarlo un derecho fundamental, la idea de reinserción sigue sosteniéndose como guía en la praxis penitenciaria y tiene como resultado la centralidad del tratamiento penitenciario.

El tratamiento penitenciario materializa este fin de reeducación y reinserción social proponiendo un programa de rehabilitación determinado desde una lógica conductista (punitivo-premial) — que hace mucho que dejó de utilizarse en el ámbito educativo-y sometido a un control, examen y valoración constantes, para la determinación de las posibilidades de acceso a mayores cotas de libertad. En este sentido, encarna la unión de lo pedagógico con lo disciplinario, con el objetivo de «corregir al delincuente», partiendo de la premisa de la obediencia.

Por otra parte, la educación es un derecho humano y fundamental, reconocido nacional e internacionalmente, y al que se le confiere una especial protección desde los ordenamientos jurídicos. Además, el fin del derecho a la educación es el pleno desarrollo de la personalidad y, en este sentido, resulta incompatible con el paradigma reeducativo que rige el tratamiento penitenciario. El pleno desarrollo de la personalidad constituye el objetivo de maximización de un desarrollo de la personalidad libre, una autodeterminación física, psíquica e informativa «exclusivamente en manos del propio sujeto» (Ryszard Kosmider 2018, 697). Se debe reconocer que esta libertad nunca será absoluta, porque se verá condicionada $-\mathrm{y}$ limitada - por el contexto sociocultural $\mathrm{y}$, en este sentido, la situación de privación de libertad constituye un contexto particularmente limitador. No obstante, el Tribunal Constitucional ha reconocido que no es constitucionalmente tolerable que la privación de libertad impida de forma absoluta la autodeterminación, no pudiendo impedirse la autodeterminación de la conducta lícita (STC 95/1986, de 10 de julio).

Así, en la situación de privación de libertad, se mantienen - aunque se vean afectados parcialmente- los derechos que emanan de la libre determinación de la personalidad. Por un lado, el derecho negativo - que consiste en una obligación de no injerencia por parte del Estado - se ve menoscabado en cierta medida, irremediablemente, como consecuencia de la situación de 
particular privación y dependencia. Sin embargo, el derecho positivo - que consiste en una obligación de promoción y favorecimiento- sí debe seguir cumpliéndose plenamente, a pesar de la situación de privación. Con ello, la posibilidad de autodeterminación - aunque se encuentre muy restringida en prisión - siempre debe favorecerse y uno de los derechos que contribuye a ello es precisamente el de la educación, como «derecho llave» (Scarfó et al. 2013,88 ), cuyo ejercicio debe quedar garantizado. En este sentido, resulta fundamental ubicar la educación como derecho positivo, y no vincularla, en ningún caso, con mecanismos punitivo-premiales que, precisamente, son la manifestación de la reducción de los derechos negativos derivados del libre desarrollo de la personalidad.

Junto a lo anterior, hay que tener en cuenta la particular problemática que existe en torno a la voluntariedad del tratamiento en prisión. Si bien la normativa exige la voluntariedad o libre aceptación del tratamiento penitenciario, de facto, debe admitirse que esta libertad es muy cuestionable. Evidentemente, la última palabra siempre la tendrá la persona presa y, en ningún caso, se le podrá forzar a la realización del tratamiento. Sin embargo, si de una correcta evolución en el tratamiento marcado depende la posibilidad de conseguir permisos o el tercer grado, ¿existe libertad para rechazar el tratamiento? A esta cuestión se refiere Gallego Díaz cuando habla de «coacciones indirectas» y explica que, para que exista voluntariedad, «es necesario que de su aceptación o rechazo no puedan derivarse consecuencias desfavorables ni ventajas para él en la ejecución de la pena» $(2019,100-103)$.

Partiendo de esta voluntariedad claramente viciada - si no, inexistentepara la aceptación del tratamiento penitenciario, si se vincula la escuela con este, colocándola como condición para optar a mayores grados de libertad, se convierte también, de facto, en una obligación. Esto genera dos efectos: 1) Se vacía de contenido el derecho, porque se articula como una injerencia del Estado en la libertad que va en contra del libre desarrollo de la personalidad -que es precisamente el objetivo del ejercicio del derecho a la educación-. 2) Supone la instrumentalización de la escuela - tanto por las personas presas como por la institución-, de forma que será susceptible de utilizarse, no por las oportunidades que ofrece, sino solo por el premio que lleva asociado. Por eso, debe defenderse que «la educación pública en las cárceles, debe ser entendida como el ejercicio de un derecho humano que no apunte al tratamiento penitenciario, sino al desarrollo integral de la persona» (Scarfó et al. 2013, 72).

Algunos sostienen que la inclusión de la escuela en el tratamiento aumenta la participación escolar. No obstante, consideramos que existen otras vías para motivar la participación que no sacrifiquen el ejercicio de un derecho. Estas vías alternativas seguramente pasan por un mayor esfuerzo por parte del profesorado para incentivar la participación, estableciendo un 
contacto directo más frecuente, tratando de hacer una correcta detección de las necesidades educativas concretas, etc. Deben encontrarse las vías para fomentar el contacto humano, y evitar la tendencia hacia la burocratización de la acción educativa y la perversión del derecho (Viedma Rojas 2017, 96). Además, no debe olvidarse a quienes asisten a la escuela porque tienen un interés real. A pesar de la instrumentalización apuntada, hay personas que acuden a la escuela libremente, interesadas en iniciar un proceso de aprendizaje que puede verse perjudicado por el hecho de compartir el aula con personas que no tienen dicho interés.

Finalmente, si la actividad educativa en ningún caso se relacionara con el tratamiento penitenciario, ¿sería, entonces, posible el pleno ejercicio del derecho a la educación en este contexto de encierro?

\section{Los límites (sombras) y las posibilidades (luces) educativas en los contextos de encierro}

¿Qué implicaciones tiene el simple hecho de que la escuela esté situada en una cárcel? ¿Se podría afirmar que en la cárcel no es posible el ejercicio del derecho a la educación plenamente debido al contexto particularmente privativo? ¿Se podría afirmar, al mismo tiempo, que la existencia de escuelas en las cárceles contribuye a una ruptura de las lógicas punitivas que hace siempre deseable su presencia?

Como ya hemos señalado antes, resultaría ingenuo afirmar que, en algún caso, las personas actuamos de manera absolutamente libre. Todas nos encontramos condicionadas por nuestro contexto sociocultural. Evidentemente, no en igual medida o de igual forma, puesto que algunos factores (clase, origen, situación administrativa, género, orientación sexual, edad, salud mental, etc.) resultan especialmente determinantes a la hora de configurar las condiciones de posibilidad del ejercicio de derechos. En este sentido, obviamente, la condición de privación de libertad constituye un factor fundamental que afecta a esas posibilidades de ejercer derechos; entre ellos, el derecho a la educación.

Las escuelas que se encuentran en contextos de encierro encontrarán límites a su funcionamiento como tales, que supondrán límites al ejercicio del derecho a la educación. Por un lado, existen algunos límites que denominamos aparentes o visibles, y en cuanto tales, seguramente son en parte modificables o suprimibles: son los límites que aparecen en la normativa penitenciaria como, por ejemplo, la limitación del acceso a Internet en el aula. Por otro lado, se encuentran otros límites que llamamos intrínsecos o inherentes, y que parecen resultar inevitables: se trata de los límites derivados del propio funcionamiento normal de una institución total. El aislamiento de la sociedad, los horarios, las rutinas, los controles, la gestión de los 
espacios, la obediencia, las autorizaciones, la homogeneización, la despersonalización, etc., son todos elementos característicos de la praxis penitenciaria. Además, lo anterior - que podría identificarse más con el régimen- se complementa con el tratamiento penitenciario: la observación de los comportamientos, la recogida de información, su registro y su evaluación punitivopremial. En este sentido, la prisión constituye una especie de «observatorio permanente», un «aparato de saber», que se rige por el «poder técnico de disciplinar» (Foucault 2012, 148-354). La escuela muy difícilmente podrá escapar de estos límites y estas lógicas. Aunque los y las docentes no participasen en los órganos de tratamiento, sería muy probablemente imposible que no se les exigiera que ofrecieran a la institución algún tipo de información sobre lo que ocurre dentro del aula y sobre el desempeño educativo del alumnado. La cárcel es totalizadora: lo quiere saber todo y atraviesa a la persona por completo. Por eso, se sostiene que las propias condiciones de privación de libertad resultan «antipedagógicas» (Ayuso 2001, 88).

Advirtiéndose estas sombras, podría afirmarse que no resulta posible ejercer el derecho a la educación en este contexto. No obstante, al mismo tiempo, es posible apreciar algunas luces: si bien el contexto de encierro es condicionante y limitativo, la educación tiene precisamente como objetivo principal que la acción educativa revierta $-\mathrm{O}$, al menos, disminuya - los condicionantes socioculturales, para posibilitar el libre desarrollo de la personalidad. Y, en este sentido, la actividad educativa en prisión puede tener un papel fundamental. Para ello, no es válida cualquier acción educativa, sino que es necesario que esta se aleje y desprenda de lógicas disciplinarias punitivo-premiales. Es decir, que no forme parte del tratamiento penitenciario y que, así, el espacio escolar sea ajeno a la ejecución, y de participación completamente voluntaria.

Siendo así, el espacio de la escuela y la acción educativa en la cárcel pueden tener efectos muy positivos en la vida de las personas privadas de libertad. Viedma y Blazich son autores que defienden esta idea. Viedma explica que, frente a la temporalidad del castigo — que consiste en la espera, la rutina y la presentización-, «la educación es la actividad que simboliza con más fuerza la temporalidad del retorno» $(2014,3)$. La actividad educativa se proyecta positivamente hacia el futuro, $\mathrm{y}$ «permite transgredir los marcos temporales y espaciales de la prisión» $(2014,16)$, puesto que es posible controlar el tiempo de dedicación al estudio y, así, tener dominio sobre una acción cotidiana - cosa que es bastante difícil en prisión-. Por su lado, Blazich aprecia el valor de la escuela en la producción de significados, «con potencia para la reformulación de los proyectos de vida de los internos» $(2007,55)$. En este sentido, la escuela podría ser un espacio de libertad dentro del contexto de encierro, «con reglas de juego propias que permita la construcción de nuevas formas de subjetivación» $(2007,58)$. La persona privada de libertad sería en 
la escuela, la alumna, cuya característica principal sería la de sujeto de derechos (del derecho a la educación), y no la de privada de aquellos.

Aquí donde el encierro es tomado como condición, la escuela puede habilitar un espacio de libertad no para «rehabilitar» para un futuro (cuando se salga en libertad), sino interviniendo en el hoy para constituirse en uno, donde la dignidad sea lo posible (Blazich 2007, 59)

En nuestra opinión, el funcionamiento independiente de las escuelas - todo lo alejadas posible de las lógicas punitivo-premiales que impone el contexto penitenciario - es lo que permitiría configurar la educación en las cárceles como una educación verdaderamente inclusiva, que trate de superar «las barreras en el contexto educativo de encierro» (Castro-Martínez 2021, 9). Siempre y, en cualquier caso, compartimos la opinión de Gil Cantero:

(...) nos parece más adecuado, más conveniente, para la calidad de vida de los presos considerar las posibilidades educativas que pueden darse y, sobre todo, que debemos crear, con todas las limitaciones conceptuales y prácticas que se quieran, que optar por centros penitenciarios donde la educación se quede a la puerta $(2010,57)$

Asimismo, volviendo al marco más amplio del ejercicio de derechos fundamentales en las cárceles, consideramos que garantizar el pleno ejercicio de aquellos derechos fundamentales no restringidos legalmente - como el derecho a la educación - es la única opción posible para evitar la inconstitucional de nuestro sistema penal, y para evitar que, en definitiva, «la justicia se detenga en la puerta de las prisiones» ${ }^{4}$.

\section{BIBLIOGRAFÍA}

Ayuso, Alejandro (2001). «La intervención socioeducativa en el tratamiento penitenciario». Pedagogía social. Revista Interuniversitaria, n. ${ }^{\circ}$ 6-7, Segunda época: 73-99.

BENITO LóPEZ, Raquel (2007). «La relación jurídica penitenciaria». Revista Jurídica de la Universidad Autónoma de Madrid, n. ${ }^{\circ}$ 15: 57-90.

BLANCO CORDERO, Isidoro (2018). «La resocialización como obligación positiva del Estado en la jurisprudencia del Tribunal Europeo de Derechos Humanos». En Derechos del condenado y necesidad de pena, dirigido por Carmen Juanatey Dorado y Natalia Sánchez-Moraleda Vilches, 261-284. Cizur Menor, Navarra: Thomson Reuters Aranzadi.

Blazich, Gladys Susana (2007). «La educación en contextos de encierro». Revista Iberoamericana de educación, n. $^{\circ}$ 44: 53-60.

CÁNovas Calatrava, Ramón (2010). «Apuntes para un estudio de la educación en prisiones». Educar(nos), n. ${ }^{\circ}$ 52: 9-13.

${ }^{4}$ STEDH, Campbell y Fell, de 28 de junio de 1984. 
Castro-Martínez, Ana M. (2021). «La calidad de la educación en centros penitenciarios de la Unión Europea. ¿Una utopía en la agenda 2030?». Revista de Estudios Europeos, n. ${ }^{\circ}$ 77, enero-junio: 5-21.

Esteban Miralles, Arnau (2020). «Escola i presó. Una radiografia del dret a l'educació a les presons catalanes». Trabajo de Fin de Grado en Derecho. Universitat Oberta de Catalunya (UOC). http://openaccess.uoc.edu/webapps/o2/handle/10609/130146 [Pendiente de publicación por el Centre d'Estudis Jurídics $i$ Formació Especialitzada (CEJFE) de la Generalitat de Catalunya]

Foucault, Michel (2012). Vigilar y castigar. Nacimiento de la prisión. Madrid: Siglo XXI.

Gallego DíAz, Manuel (2013). «Tratamiento penitenciario y voluntariedad». Revista de Estudios Penitenciarios, n. $^{\circ}$ Extra: 99-118.

Gil Cantero, Fernando (2010). «La acción pedagógica en las prisiones. Posibilidades y límites». Revista Española de Pedagogía, n. ${ }^{\circ}$ 245: 49-64.

GOFFMAN, Erwing (2001). Internados. Ensayos sobre la situación social de los enfermos mentales. Buenos Aires: Amorrortu.

LaSagabaster Herrarte, Iñaki (1994). Las relaciones de sujeción especial. Madrid: Civitas.

MaPelli CAFFARENA, Borja (1992). «Las relaciones especiales de sujeción y el sistema penitenciario». Estudios Penales y Criminológicos, n. ${ }^{\circ}$ 16: 281-326.

MARTíNEZ EsCAMILla, Margarita (1998). «Derechos fundamentales entre rejas. Algunas reflexiones acerca de los derechos fundamentales en el ámbito penitenciario, al tiempo que un comentario de la jurisprudencia constitucional al respecto». Anuario de Derecho Penal y Ciencias Penales, Tomo 51, Fasc/Mes 1-3: 245-262.

MAta y Martín, Ricardo M. (2011). «El principio de legalidad en el ámbito penitenciario». Revista General de Derecho Penal, n. ${ }^{\circ}$ 14: 121-166.

RIVERA BEIRAs, Iñaki (1997). La devaluación de los derechos fundamentales de los reclusos. Barcelona: Bosch.

- (2006). La cuestión carcelaria. Historia, Epistemología, Derecho y Política penitenciaria. Buenos Aires: Editores del Puerto.

RoDríGUEZ YAGÜE, Cristina (2012). «El derecho a la educación en el sistema penitenciario español». Revista La Ley Penal, n. ${ }^{\circ}$ 96-97: 66-91.

Ruiz CABello, Úrsula. y LóPez-RibA, José María (2019). «Consideraciones sobre la educación en prisión: un análisis de la realidad española a partir de la lectura de Stateville». Papers, Vol. 104, n. ${ }^{\circ}$ 3: 593-599.

RYSZARD Kosmider, Mariusz (2018). «El contenido jurídico del concepto del libre desarrollo de la personalidad con referencia especial a los sistemas constitucionales alemán y español». Revista de Derecho UNED, n. ${ }^{\circ}$ 23: 667-706.

SANTANA RAMOS, Emilia María (2014). «Las claves interpretativas del libre desarrollo de la personalidad». Cuadernos Electrónicos de Filosofía del Derecho, n. ${ }^{\circ}$ 29: 99-113.

ScArfó, Francisco, PÉrez Lalli, Florencia y Montserrat, Ivana (2013). «Avances en la Normativa del Derecho a la Educación en Cárceles de la Argentina». Educação \& Realidade, Porto Alegre, Vol. 38, n. ${ }^{\circ}$ 1: 71-92.

Solar Calvo, Puerto (2019). «Consecuencias penitenciarias de la relación de sujeción especial. Por un necesario cambio de paradigma». Anuario de Derecho Penal y Ciencias Penales, Vol. LXXII: 777-809. 
Tamarit Sumalla, J-M., García Albero, R., Rodríguez Puerta, M-J. y Sapena Grau, F. (2005). Curso de Derecho Penitenciario (2 ${ }^{\mathrm{a}}$ ed.). Valencia: Tirant lo Blanch.

Viedma Rojas, A. (2014). «Tiempo de estudio vs tiempo de prisión: identidad y resistencia frente al tiempo». Crisis y cambio. Propuestas desde la Sociología: actas del XI Congreso Español de Sociología. Universidad Complutense de Madrid. Facultad de Ciencias Políticas y Sociología. 10-12 de julio de 2013, coordinado por Heriberto Cairo Carou y Lucila Finkel Morgenstern, Vol. 3: 236-244.

Viedma RoJas, Antonio (2017). «La situación de la educación en prisión en España: realidades y expectativas de transformación». En Los derechos de los reclusos y la realidad de las cárceles españolas. Perspectivas sociales, políticas, jurídicas y filosóficas, editado por Ignacio Campoy Cervera, 95-117. Madrid: Dykinson. 


\title{
EL EJERCICIO DE DERECHOS FUNDAMENTALES EN LA CÁRCEL: EL CASO DEL DERECHO A LA EDUCACIÓN EN LAS CÁRCELES CATALANAS
}

The exercise of fundamental rights in prison: the case of the right to education in catalan prisons

\author{
Lorena Alemán Aróstegui \\ Investigadora predoctoral contratada (FPU 18/04843) en Derecho penal \\ Universidad Pública de Navarra \\ Arnau Esteban Miralles \\ Maestro del Departament d'Educació de la Generalitat de Catalunya \\ en un Centro de Formación de Adultos/as ubicado en un Centro Penitenciario \\ Graduado en Derecho (UOC)
}

http://dx.doi.org/10.18543/ed-69(2)-2021pp15-41

\section{Copyright}

Estudios de Deusto es una revista de acceso abierto, lo que significa que es de libre acceso en su integridad. Se permite su lectura, la búsqueda, descarga, distribución y reutilización legal en cualquier tipo de soporte sólo para fines no comerciales, sin la previa autorización del editor o el autor, siempre que la obra original sea debidamente citada y cualquier cambio en el original esté claramente indicado

Estudios de Deusto is an Open Access journal which means that it is free for full access, reading, search, download, distribution, and lawful reuse in any medium only for non-commercial purposes, without prior permission from the Publisher or the author; provided the original work is properly cited and any changes to the original are clearly indicated. 